\title{
POR OUTRO IMAGINÁRIO MEDIEVAL: NOS BASTIDORES DA LITERATURA (UM OLHAR DESDE O NOVO MEDIEVALISMO)
}

\author{
IN SEARCH OF ANOTHER MEDIEVAL IMAGERY: ON THE \\ BACKGROUND OF LITERATURE (A LOOK FROM THE NEW \\ MEDIEVALISM)
}

\author{
Juan Ignacio Jurado Centurion LOPEZ*
}

\begin{abstract}
Resumo: Tratar a Idade Média apresenta um dilema: qual é o referencial que devemos adotar na hora de tentar nos aproximar deste período da nossa história? Desde a sua presumida finalização, o medievo foi objeto de muitas críticas, principalmente desfavoráveis. Apreciações, na maioria das vezes, com o amparo de grandes intelectuais de cada época. Para os humanistas, o período nada produz de relevante; para os ilustrados do século XVIII, o medievo pouco ou nada tinha a aportar. A esperança que abrigava o resgate das tradições parecia que propiciariam, no romantismo, um ambiente adequado para amenizar $\mathrm{o}$ ataque contra o medievo. Porém, para a maioria dos intelectuais, a idealização do período desviou o foco e criou uma fantasia de cavaleiros, torneios e alta dose de cortesia. $\mathrm{O}$ século $\mathrm{XX}$, com o seu revisionismo, ajudou muito na hora de repensar esta desvirtuação histórica e se tentou redimir, ou, pelo menos, conciliar, a narração dos fatos históricos através da visão mais nítida que nos proporciona o estudo do cotidiano, das mentalidades na configuração do imaginário medieval. Competirá ao século atual pensar, através de linhas teóricas como o Novo Medievalismo e sua proposta multidisciplinar, os conhecimentos sobre o medievo. Um novo século para um novo imaginário medieval. Este trabalho pretende dar a sua contribuição e, para isso, trataremos quatro aspectos que nos permitiram enxergar um possível novo imaginário revelado nas entrelinhas da história e da criação literária: a utopia, o amor cortês, a imagem da mulher e o ideal cavalheiresco.
\end{abstract}

Palavras-chave: Novo Medievalismo. Estudos do Imaginário. Medievo. Literatura. História.

\begin{abstract}
Treating the Middle Ages presents a dilemma: which referential should be adopted when trying to approach this period of our history? Since its presumed end, the Middle Ages have been the object of many, often unfavorable, criticisms, carried out under the protection of great intellectuals of each era. For the humanists, the period offered nothing relevant; for the intellectuals of the $18^{\text {th }}$ century, the Middle Ages, had nothing to contribute. It seemed that the hope that housed the rescue of local traditions and legends would provide, during the romanticism, a propitious environment to soften the attack against the Middle Ages; however, for most intellectuals, the idealization of the period diverted the focus and created a fantasy of knights, tournaments and high doses of courtesy. The revisionism of the $20^{\text {th }}$ century considerably helped to rethink this historical distortion and tried to redeem, or, at least, reconcile the narration of historical events through the clearer vision offered by the study of daily life, the mentalities in the configuration of the medieval imagery. It is up to the current century to go on and rethink the information about this period, through theoretical lines such as New Medievalism and its multidisciplinary proposals. A new century for a new medieval imagery. This paper aims to contribute for the discussion by treating four aspects that have allowed to see a possible new imagery revealed between the lines of history and the literary creation: utopia, courtly love, the female image and the chivalric ideal.
\end{abstract}

Keywords: New medievalism. Studies of imageries. Medieval Literature. History.

\footnotetext{
* Doutor em Teoria da Literatura pela Universidade Federal de Pernambuco (UFPE). Professor do Programa de Pós-Graduação em Letras (PPGL/UFPB). E-mail: juanig@ @terra.com.br. ORCID: https://orcid.org/0000-00029880-6170
} 


\section{Introdução}

Um dos grandes dilemas que se apresentam na hora de embarcar nos estudos medievais deriva da dificuldade que o estudioso enfrenta quando se situa diante da dupla visão, entre a recreação fantasiosa e o rigor histórico, que sobre este período histórico foi se construindo ao longo dos séculos. Desde a sua controversa delimitação temporal, a fins do século XV, até hoje, são múltiplas as visões sobre o Medievo que foram vertidas por um sem fim de vozes, desde historiadores até filósofos, religiosos, poetas, dramaturgos, pintores e um longo etecetera. Todos eles deixaram de maneira direta ou indireta a sua visão desse período. Grandes nomes da ciência mostraram as suas opiniões sobre a Idade Média, e ainda que tivesse outras vozes favoráveis, coube a todos eles deixar a sua apreciação negativa da época mais "tenebrosa" da nossa história e, com esses seus julgamentos, irem forjando um dos mitos mais consolidados e ao mesmo tempo mais injustificados da historiografia ocidental. A sucessão de crenças, que estas críticas trouxeram consigo, ajudou a cristalizar uma ideia da qual até hoje nos é muito difícil escapar e não parece que a mesma esteja com a sua data de validade próxima a vencer. Uma simbólica Idade Média com as suas habituais vestes obscuras, a onipresente violência nas relações sociais e a sufocante presença da Igreja em quase todos os estágios da vida, tem sido o marco ideal para forjar essa imagem estereotipada do período, seja a sua forçada idealização na literatura, no cinema, na televisão ou nos exitosos jogos de vídeo que hoje em dia são muito mais eficientes na hora de propagar esses mitos que todos os meios de divulgação expostos antes. A Idade Média está de moda, porém poucos se importam se a representação que dela se faz peca de fantasia e como adverte Mínguez (2006) se converte em um mero objeto de entretenimento sem nenhum rigor histórico. E não somente este "literaturizar" a Idade Média é o problema; como lembra o mesmo autor, a manipulação da história com fins políticos foi ademais muito prolífica ao longo dos séculos e muito mais o foi durante o século passado, e até hoje o medievo segue sendo empregado de forma ideológica.

As novidades proporcionadas por tais correntes e outras correntes de jato menor fornecem ar suficiente para oxigenar e dar um novo impulso à história, que deve se livrar definitivamente do fardo representado por dois problemas que a afetaram seriamente no século 20 e continuam a afetá-la no tempo presente. Um é tentar transformá-la em objeto de mero entretenimento, como se fosse uma simples obra literária, desprovida de qualquer pretensão crítica. O outro problema é usá-la como um instrumento político para servir para legitimar o poder ou governo da época. Em outras 
palavras, a história nem se pode "literaturizar" nem deve ser colocada a serviço exclusivo de interesses partidários (MINGUEZ, 2006, p. 132, tradução do autor). ${ }^{1}$

Para o historiador francês Jacques Le Goff, essa visão deturpada do medievo teve a sua origem durante a Renascença e foi se agravando nos séculos posteriores, entre o desprezo e as pouco favoráveis idealizações posteriores.

\begin{abstract}
A hostilidade, e inclusive o desprezo, que experimentou e muitas vezes manifestou a elite cultural da época denominada Renascimento para com a Idade Média a partir do século XIV, e que se faria mais patente no século XV e sobre todo ao longo do XVI, se transformou e inclusive agravou mais tarde, particularmente no século XVIII, por causa dos ilustrados do Século das Luzes. Esses pensadores chegaram inclusive a qualificar a Idade Média como uma época de obscurantismo, Dark Ages em inglês. Essa condenação da Idade Média se baseava sobre todo na necessidade dos homens do Renascimento de voltar á Antiguidade clássica e aos seus grandes mestres (Aristóteles e Platão na Grécia, Cicero e Séneca em Roma), que o pensamento medieval tinha ignorado e contra os quais se teria afirmado (LE GOFF, 2014, p. 57).
\end{abstract}

E assim, esse é o dilema que nos é apresentado quando assistimos um dos seriados de televisão mais populares dos últimos anos: Game of Thrones. O seriado, baseado na saga literária homônima do agora celebérrimo escritor George. R. Martin, retrata um mundo atemporal. Apesar de não estar vinculado diretamente a nenhum período histórico concreto, o público não tem muita dificuldade na hora de associar a sua história ao medievo e isso acontece precisamente pela sucessão de estereótipos, entre a barbárie imaginada pelo iluminismo e a idealização romântica, que este popular seriado apresenta ao longo da sua narrativa. São esses aspectos os que dão sentido ao dilema e à questão que assinalamos desde as primeiras linhas. Como podemos traçar um retrato com um maior rigor histórico do Medievo se, como já observamos previamente, os encarregados dessa missão foram os mesmos que desconstruíram essa imagem e foram alimentando essa visão idealizada que até hoje temos sobre ele?

É relevante o elenco de mitos que sobre a Idade Média foram se sedimentando nessa visão alterada: atraso cultural e tecnológico, períodos de extrema fome, de terríveis doenças, de uma sufocante presença da religião e um longo etc. Dentre todos eles vamos destacar um que tem a capacidade de remeter-nos aos outros aspectos e ao mesmo tempo nos servirá de nexo para

\footnotetext{
${ }^{1}$ No original: "Las novedades aportadas por tales corrientes y otras de chorro menor aportan aire suficiente para oxigenar y dar un nuevo impulso a la historia, que debe desprenderse definitivamente del lastre que suponen dos problemas que le han afectado de manera grave en el siglo XX y continúan haciéndolo en el tiempo presente. Uno es pretender convertirla en un objeto de mero entretenimiento, como si se tratara de una simple obra literaria, desprovista de cualquier pretensión crítica. El otro problema es utilizarla como instrumento político para servir a la legitimación del poder o del gobierno de turno. En otras palabras ni se puede "literaturizar" la historia ni debe ponerse al servició exclusivo de intereses partidistas."
} 
conectar com as teorias literárias que nos servirão de base para a análise dos fragmentos escolhidos.

No seu derradeiro ensaio, o medievalista francês Jacques Le Goff (2016), depois de toda uma vida dedicada a questionar a controversa periodização tradicional da historiografia ocidental, tenta demostrar a longevidade extra da Idade Média, a qual, segundo ele, chegaria até as revoluções burguesas do século XVIII e até consegue enxergar novos modos de feudalismo em diversas manifestações da atualidade. $\mathrm{O}$ historiador disserta, como observamos linhas acima, sobre os primeiros responsáveis de alimentar os mitos que, sobre esse período histórico, nutrem esse controverso imaginário que como observamos há pouco se continuam filtrando em muitas produções culturais e vive até hoje nos livros de textos que divulgam entre as novas gerações essas falsas crenças sobre o medievo.

\footnotetext{
Da minha parte, penso que a mudança de período, ao fim da longa Idade Média, $\mathrm{s}$ situa a meados do século XVIII. Corresponde aos progressos da economia rural, advertidos e teorizados pelos fisiocratas, à invenção da máquina de vapor concebida pelo francês Denis Papin (1647-1712) em 1687, e realizada pelo inglês James Watt (1736-1819) em 1769; o nascimento da indústria moderna que da Inglaterra se estenderia para o continente. No âmbito filosófico e religioso, a longa Idade Média chega ao seu fim com a obra que introduz o pensamento racional e ateu, a ciência e a tecnologia moderna, e enciclopédia, cujos brilhantes promotores serão Diderot e Voltaire. Por último, o fim do século XVIII corresponde, no âmbito político, o movimento antimonárquico decisivo da Revolução francesa (LE GOFF, 2016, p. 91, tradução do autor $)^{2}$.
}

As contribuições intelectuais desse historiador francês ajudaram bastante, durante o século passado, a derrubar muitos desses mitos e ir criando uma imagem menos desfavorável dessa época. Naquele que pode ser considerado o epílogo há mais de meio século de estudos dedicados, junto com o grupo da Escola dos Annales, Le Goff (2015), em uma longa reflexão questiona a canônica e controversa divisão da história. O historiador repassa os principais aspectos que configuram o imaginário medieval que se foi construindo ao longo dos séculos desde os relevantes aspectos tecnológicos até aqueles referidos estritamente ao campo das humanidades. Le Goff faz a sua particular observação e a ressignificação de conceitos como o

\footnotetext{
${ }^{2}$ No original: "Por mi parte, opino que el cambio de periodo, el fin de la larga Edad Media, se sitúa a mediados del siglo XVIII. Corresponde a los progresos de la economía rural advertidos y teorizados por los fisiócratas; a la invención de la máquina de vapor concebida por el francés Denis Papin (1647-1712) en 1687, y realizada por el inglés James Watt (1736-1819) en 1769; al nacimiento de la industria moderna que de Inglaterra se extendería a todo el continente. En el ámbito filosófico y religioso, la larga Edad Media toca su fin con la obra que introduce el pensamiento racional y ateo, la ciencia y la tecnología modernas, la Enciclopedia, cuyos más brillantes promotores serán Diderot y Voltaire. Por último, el fin del siglo XVIII corresponde, en el ámbito político, al movimiento antimonárquico decisivo de la Revolución francesa".
} 
da Escolástica que, segundo ele, sempre foi injustamente desdenhada por ignorar a razão como instrumento para atingir o campo das ideias.

\begin{abstract}
Entre o século XV e o final do XVIII, houve entre os pensadores o sentimento de que o mergulho nas trevas que o período medieval representava para eles era acompanhado de um forte recuo do pensamento racional, que cedia lugar ao miraculoso, ao sobrenatural, ao apaixonado. Ora, a maioria dos clérigos da e Média, assim como o sistema de educação em vigor nas escolas, referiram-se quase constantemente à razão, e mais precisamente à ratio, sobe seus dois sentidos: o do pensamento e o do calculo. (...) No século XIII, grandes escolásticos, como Alberto, o Grande, ou Tomás de Aquino, retomam no Livro de definições, de Isaac Israeli (séculos IX-X), a ideia de que "a razão nasce da sombra da inteligência" (LE GOFF, 2015, p. 77-78).
\end{abstract}

Para o medievalista Jaume Aurell (2016), se faz necessária uma revisão crítica do período, dentro dos postulados apresentados pelo Novo medievalismo, que nos permita um olhar menos adulterado. E esse olhar teria que passar por um adequado equilíbrio entre o presentismo e o preterismo.

Todas as minhas reflexões (...) estão governadas pela minha convicção que o historiador deve manter um adequado equilíbrio entre o respeito pela realidade histórica, por um lado e a conveniência de ajustar seu discurso às demandas da sociedade que lhe rodeia. O problema é que qualquer polarização dessa equação lhe levaria se deixar levar por um excessivo preterismo ou presentismo, respectivamente (AURELL, 2016, p. 11, tradução do autor). ${ }^{3}$

Com uma visão mais abrangente, ou como o próprio autor declara, através de um olhar poliédrico, o Novo medievalismo estuda o período histórico desde uma perspectiva que não se restringe à Idade Média dos que a protagonizaram, senão também através da impressão de aquelas vozes que a retrataram ao longo dos séculos posteriores.

Contando com o peso de presentismo na recuperação do passado, não é estranho que se tenha chegado a definir o medievalismo não como o estudo da Idade Média, mas também - e talvez mais propriamente- como a aplicação dos modelos medievais às necessidades contemporâneas e, em um terceiro nível, como o espírito que se respira na Idade Média em todas as manifestações da arte e do pensamento contemporâneo. Um novo âmbito do medievalismo se impõe, ao considerar não só como o estudo da Idade Média em si mesmo, se não dos investigadores, artistas e escritores que, ao longo da história, construíram a ideia da Idade Média que nós herdamos (AURELL, 2004, p. 386, tradução do autor). ${ }^{4}$

\footnotetext{
${ }^{3}$ No original: "Todas mis reflexiones (...) están gobernadas por mi convicción de que el historiador debe mantener un adecuado equilibrio entre el respeto por la realidad histórica, por un lado y la conveniencia de ajustar su discurso a las demandas de la sociedad que le rodea. El problema es que cualquier polarización de esa ecuación le llevaría a dejarse llevar por un excesivo preterismo o presentismo, respectivamente."

${ }^{4}$ No original: "Contando con el peso de presentismo en la recuperación del pasado, no es extraño que se haya llegado a definir el medievalismo no sólo como el estudio de la Edad Media, sino también -y quizás más propiamente - como la aplicación de los modelos medievales a las necesidades contemporáneas y, en un tercer
} 
Assim, esse novo olhar, através da análise crítica mais rigorosa, nos pode ajudar a traçar um novo retrato dessa época que considere tanto o dito como o não dito. O silêncio assim como as omissões e demais estratégias retóricas empregadas podem ser agora de grande ajuda para redimir essa desastrosa imagem que sobre o medievo ainda temos hoje em dia em alguns âmbitos.

No último terço do século passado, a historiadora francesa Régine Pernoud (1978) observava que até aqueles dias muitas dessas caraterísticas estavam ainda presentes no imaginário popular. E apesar de naqueles momentos a paixão suscitada pelo medievo ter provocado um paulatino distanciamento dessas errôneas crenças, ainda se estava muito longe de vê-las extintas. Quase meio século depois se pode afirmar que pouca coisa mudou. Novos suportes tecnológicos como os videogames, como Age of empires, ou aplicativos, como Look história, continuam semeando esses velhos clichês para as novas gerações. Uma Idade Média cinematográfica distorcida com a presença sufocante da Igreja em todas as manifestações da sociedade, a sua desmedida violência, com o seu retrato grotesco dos seus protagonistas e com um desmedido atraso cultural e tecnológico, sempre venderá muito mais que o retrato ameno e singelo proposto por alguns roteiristas do final do século passado quando se aproximaram à biografia de figuras capitais do período, como a de São Francisco ou a de Santa Clara. As artes visuais, assim como os romances mais exitosos que tem como pano de fundo esse período histórico, quase sempre, salvo raras exceções, alimentaram, alimentam e alimentarão esse modelo e contribuíram para perpetuar esse particular modo de enxergar a Idade Média.

Nessa mesma linha de pensamento, o professor Antonio Rubial García (2014) encontra nas expressões que empregamos até hoje em nosso dia a dia um resquício de um período que, pelo que demostramos no uso destas fórmulas, mostra que ainda conservamos um acentuado apego a esse período histórico e quase sempre denotando um controverso aspecto negativo.

Continuamos a chamar uma casa luxuosa de palácio; um jantar pode ser majestoso, imagem que às vezes envolve o alto clero para também expressar o luxo: bocatto di cardinale. Quando algo é considerado muito valioso, é a joia da coroa. Existem expressões como clima / ambiente imperante / reinante; sonha-se com príncipes azuis que aparentemente têm sangue dessa cor. Existe realeza no xadrez, assim como entre abelhas, metais, tecidos, baralhos, festas de Natal e borboletas. O fato de coroar significar "aperfeiçoar, completar uma obra" nos apresenta outra manipulação linguística: coroa é igual à perfeição; $\mathrm{O}$ mesmo acontece com o adjetivo majestoso, aplicado, por exemplo, a uma paisagem. Todos nós queremos viver como um rei e

nivel, como el espíritu que late de la edad media en todas las manifestaciones del arte y del pensamiento contemporáneo. Un nuevo ámbito del medievalismo se impone, al considerarlo no sólo como el estudio de la Edad Media en sí misma, sino de los investigadores, artistas y escritores que, a lo largo de la historia, han construido la idea de la Edad Media que nosotros hemos heredado." 
continuamos a chamar de nobre, aquele de virtudes louváveis, e o vilão (que era o camponês habitante da cidade) de malvado. Até pouco tempo atrás, as crianças mexicanas eram obrigadas a responder "mande" quando perguntadas, uma palavra que se refere aos mandamentos bíblicos e a uma sociedade de servilismo e submissão (GARCÍA, 2014, p. 15-16, tradução do autor). ${ }^{5}$

O estigma, como já foi observado previamente, criado pela visão idealizada afetou, como não poderia ser de outra maneira, a interpretação e a análise das obras literárias deste período, condenando-as, em muitos casos, a uma forçada exegese que dispensava as outras possíveis leituras. Com isso, a literatura cavalheiresca do Cantares de Gesta, muito útil para reforçar em determinadas épocas aos ideários políticos, se reduz tradicionalmente a glorificação do idealizado herói numa época marcada pela constante presença das ações bélicas e o forte apelo à carreira militar. Igualmente, o amor cortês, entre os desejos da Igreja e de uma refinada nobreza, se interpretou como a exaltação do amor até uns limites exacerbados que escapavam da realidade. Contudo, por trás dessas generalizações, as criações literárias evidenciam, mesmo que de forma velada, outras intenções. As quais muitas vezes não coincidem com essa primeira leitura.

Com base nessa ótica, pode-se dizer que a literatura não é o espelho do mundo social, mas parte constitutiva desse mundo. Ela expressa visões de mundo que são coletivas de determinados grupos sociais. Essas visões de mundo que são informadas pela experiência histórica concreta desses grupos sociais que as formulam, mas são também elas mesmas construtoras dessa experiência (FACINA, 2004, p. 25).

Nas próximas páginas vamos tentar visualizar outra Idade Média e para isso visitaremos algumas manifestações literárias, como os já citados casos da literatura cavalheiresca ou da cortesia amorosa, além da vertente utópica e da visão medieval da mulher que aparece de forma velada nos bastidores de algumas criações do período medieval. Como pressupostos teóricos de apoio trazemos o pensamento crítico de historiadores ou críticos literários como Régine Pernoud, Jaume Aurell, Hilário Franco Jr. ou Claudio Sanchez Albornoz, entre outros. As suas particulares teorias sobre o sentir e o proceder da sociedade medieval nos aportaram o material

\footnotetext{
${ }^{5}$ No original: "Seguimos llamando palacio a una casa lujosa; una cena puede ser regia, imagen que en ocasiones involucra al alto clero para expresar también lujo: bocatto di cardinale. Cuando algo se considera muy valioso es la joya de la corona. Existen expresiones como clima/ambiente imperante/reinante; se sueña con los príncipes azules que al parecer tienen la sangre de ese color. Hay realeza en el ajedrez, así como entre abejas, metales, casimires, barajas, fiestas navideñas y mariposas. El que coronar signifique "perfeccionar, completar una obra" nos presenta otra manipulación lingüística: corona es igual a perfección; igual sucede con el adjetivo majestuoso, aplicado por ejemplo a un paisaje. Todos deseamos vivir a cuerpo de rey y seguimos denominando noble, al que tiene virtudes encomiables y villano (que era el campesino habitante de la villa) al malvado. Hasta hace no mucho tiempo a los niños mexicanos se les obligaba a responder "mande", cuando se les preguntaba algo, palabra que remite a los mandamientos bíblicos y a una sociedad de servilismo y sumisión."
} 
necessário para ter acesso à literatura do período desde outra visão que entrecruza o aspecto histórico e o literário, para fazer outro retrato menos idealizado da sociedade medieval e de seus anseios, refletidos, às vezes de forma velada e consciente, e outras de um modo inconsciente, nas entrelinhas dos textos.

A interpretação de textos medievais tem se alimentado tradicionalmente dos mitos e as falsas crenças que durante séculos foram forjando, muitas vezes desde a academia, uma imagem incompleta e distorcida da Idade Média. Esse fato tem condicionado tanto as aproximações à literatura do período, como a presença dela em criações posteriores. Tem sido deste modo como muitas dessas falsas representações sobre este período sobrevivem até os dias de hoje e se obstinam em permanecer, como afirma Pernoud (1977) até em certos núcleos acadêmicos. A historiadora francesa admite que nem sempre foi possível para o público geral o contato com a Idade Média, fosse pela falta de informações disponíveis ou pela insignificância das mesmas em algumas publicações como enciclopédias ou dicionários, porém, fica surpresa quando constata que no mundo acadêmico, espaço dos eruditos, a desinformação e a presença desses estereótipos que citávamos anteriormente também era recorrente.

Falamos aqui das obras de vulgarização acessíveis ao público médio, porque é evidente que os trabalhos de erudição abundavam desde ha muito. Mas, para os atingir, havia toda uma serie de obstáculos a transpor: primeiro, o acesso as bibliotecas que os encerram; depois, a barreira da linguagem de iniciados em que a maior parte e redigida. Se bem que o nível geral possa ser fornecido pela pergunta que serviu de base a um encontro do Circulo Católico dos intelectuais franceses de 1964: «A Idade Média seria civilizada?" »Sem a menor ponta de humor; podemos estar certos de que se tratava de intelectuais na sua maior parte universitários, e de universitários na maior parte com responsabilidades. Os debates realizavam-se em Paris, na Rue Madame. Desejamos, para conforto moral dos participantes, que nenhum tenha tido, ao voltar para o seu domicílio, de passar diante da Notre-Dame de Paris. Podia ter sentido um certo mal-estar. Mas não, estejamos tranquilos: de qualquer modo, o universitário com responsabilidade apresenta uma incapacidade física em ver o que não esta de acordo com as noções que o seu cérebro segregou. De qualquer maneira ele não terá, pois, visto a Notre-Dame, mesmo que o seu caminho o levasse a Place du Parvis (PERNOUD, 1977, p. 7-8).

Como observa Walter, em entrevista concedida à pesquisadora da Universidade de México Blanca Solares (2007), se pode entender o imaginário como o conjunto de procedimentos simbólicos relativos às representações humanas. Um mundo simbólico que é o modo de expressão do homem liberado da sua racionalidade e assim o autor conclui (p. 142, 144) que estudar o imaginário é pesquisar o sentido da aventura humana no planeta e pode ser um meio para lutar contra a discriminação cultural. Cada cultura cria seu próprio imaginário acomodado, muitas vezes de forma estratégica à sua própria realidade, e para realizar esta tarefa 
epistemológica se faz necessário colocar em questão outros imaginários que possam ser conflitantes. Influenciados pela máxima do constante progresso, os imaginários que sucederam o período medieval estigmatizaram este e com esse proceder nos privaram, em alguns casos até hoje de apreciar a Idade Média de um modo mais favorável e resgatando dela tudo aquilo que nos poderia ajudar a melhorar o tempo presente.

Os valores da Idade Média, que a modernidade não reconhece e parece querer destruir, são todos valores ligados ao sagrado e ao respeito pelo proibido. $\mathrm{O}$ mundo medieval respeitou a natureza, onde encontrou remédio para seus males, o mundo contemporâneo explora e destrói implacavelmente a natureza a ponto de se autodestruir (MORALES, 2007 , p. 146 , tradução do autor $)^{6}$.

Ainda para o Diretor do Centro de Investigaciones sobre el Imaginario de la Universidad Stendhal-III, de Grenoble na Franca, ignorar a Idade Média é o mesmo que ignorar tudo aquilo que esteve na origem do nosso mundo atual, a língua e a cultura em particular (p. 147).

\section{A utopia literária e os eternos anseios da sociedade por um mundo melhor}

Segundo Hilário Franco Jr. (1992), é absurdo que um termo, que nasce da pena de Thomas More, no início do século XVI, mais concretamente no ano da publicação da sua obra prima: Utopia (1516), possa ser aplicado veementemente para designar situações acontecidas em períodos anteriores como a Idade Média, porém, isso não nos impede que, substituindo o termo criado por More no alvorecer de uma nova época denominada de Idade moderna ou de Renascença, denotemos a sublime e constante aspiração por parte da humanidade por um mundo melhor no âmbito da utopia. Utopia que, como observa Hilário Franco (1992), se configura através da confluência de três elementos constitutivos: o mito, a ideologia e a liturgia. Estes conformam todas as utopias que, ao longo de sua trajetória, a humanidade tem gerado na tentativa de exorcizar, se nos é permitido o uso deste peculiar termo, seus desejos por uma melhora social.

De fato, utopia é a negação de um presente medíocre e sufocante, é o espaço futuro sem limites, sustentado pelo desejo, é sonho apaziguador de regresso à perfeição das origens, é reencontro do homem consigo mesmo. [...] De qualquer maneira, a imaginação utópica é um produto da História que nega a História [...] "A utopia é

\footnotetext{
${ }^{6}$ No original: "Los valores de la Edad Media, que la modernidad no reconoce y parece querer destruir, son todos los valores ligados a lo sagrado y al respeto de lo prohibido. El mundo medieval respetaba la naturaleza, donde encontraba remedio a sus males, el mundo contemporáneo explota y destruye despiadadamente a la naturaleza hasta el punto de destruirse a sí mismo."
} 
nostálgica, busca a harmonia edênica, é, portanto, um mito projetado no futuro.” (FRANCO JR., 1992, p. 12, 13).

Não cabe aqui elencar todas as experiências que a humanidade já protagonizou para tentar melhorar a sua condição social, sejam elas reconhecidas como manifestações utópicas ou não. Segundo o mesmo autor (1992), as manifestações utópicas da Idade Média podem ser classificadas de acordo com a procura no seu sentido amplo de cada uma delas:

\section{- Utopia da Paz (Claustro)}

- Utopia da Fraternidade (As ordens religiosas)

- Utopia da alternativa (Heresias)

- Utopia da simplicidade (O Bucolismo)

- Utopia da Igualdade Jurídica (Robin Hood)

- Utopia da Abundância: (A Cocanha)

Em benefício do nosso objetivo podemos observar que por trás de cada uma dessas manifestações utópicas, nas suas entrelinhas, é possível enxergar outro imaginário capaz de derrubar os alicerces da historiografia tradicional e nos revelar, nos bastidores, uma Idade Média mais próxima da realidade vivida pelos nossos ancestrais. O país da Cocanha nos revela o desejo, ou talvez fosse melhor dizer o sonho de ter fartura frente à escassez, a utopia da alternativa, nas entrelinhas, nos mostra que o poder central de Roma não era tão poderoso como nos contaram e que a Idade Média teve os seus insubordinados através de diferentes heterodoxias que contestavam esse poder central e anteciparam o movimento reformista posterior. Cada uma das utopias assinaladas por Hilário Franco Jr. traz no seu bojo uma aspiração humana que pode nos ajudar a vislumbrar nos bastidores outra Idade Média menos idealizada e mais realista. Esse desejo por um mundo melhor se traduz até hoje em muitos aspectos das nossas vidas: desde a cultura, a política, a ciência e todos eles são o alimento, com maior ou menor sucesso, de criações literárias, programas eleitorais, projetos de investigação, etc. Um dia todos esses registros, que podem ser considerados como documentos de primeira mão, talvez possam formar um corpus documental que ajude as futuras gerações na tentativa de traçar um retrato de seu passado fora das exigências de uma disciplina marcada pela sua rígida e ideológica exegese histórica. Pelo controverso retrato traçado por uma crítica literária canônica que muitas vezes não reflete o verdadeiro desejo de um determinado grupo social e se restringe a representar o grupo ao qual o autor pertence ou a idealizar, muitas vezes de forma 
depreciativa, aquele outro que não lhe incumbe. O imaginário, como já foi notado antes, se constitui como uma forma de representação simbólica que quase sempre é atravessada por estratégicas manipulações que são o produto de preconceitos, de prejuízos contra determinadas formas de pensar ou de viver.

\section{As outras intenções por trás da cortesia medieval}

Dentre todas as representações idealizadas da vida social no Medievo talvez seja a da cortesia e sua extensão literária no amor cortês a que experimentou o mais importante desvio do propósito original da mesma. Tratada como um modo de refinamento social protagonizado por um grupo dominante e materializado através da literatura, fora do espectro desta minoritária aristocracia poucas foram as mulheres que sentiram que algo mudava, como consequência desta manifestação "romântica", nas relações sociais entre os dois gêneros. Inclusive aquelas poucas que poderiam ter tido algum trato de favor derivado de este refinado proceder, também não experimentaram muita diferença em suas vidas. Nos últimos anos são muitos os estudos que têm tratado de observar essa outra visão da cortesia e do amor idealizado por trás dessa fantasiosa representação. Por um lado aqueles que não a enxergam como uma fantasia amorosa e gentil e, de outro modo, a apreciam como uma velada denúncia à injusta situação social provocada pelos arranjos matrimoniais entre as classes privilegiadas no contexto das mudanças sociais metaforizadas pelo arquitetônico câmbio dos violentos modos do bélico castelo até a refinada vida palaciana, por outro, os que enxergam a cortesia na literatura medieval como um disfarçado ataque contra a emancipação feminina, que caracterizou os últimos séculos da denominada Idade Média. A idealização da amada e o refinamento dos modos seria um meio de impedir a ascensão social da mulher como veremos na continuação.

No seu magnífico ensaio sobre o amor cortês, Jose D’Assunção Barros (2015) percorre diferentes hipóteses para o surgimento da cortesia na literatura medieval, principalmente entre os séculos XI e XIV. Entre as várias teorias, para esta eclosão cortesã, apresentadas pelo autor, destaca a questão do arranjo matrimonial, dos casamentos de conveniência como um dos possíveis incentivos para a aparição desse velado código que é parte integrante do jogo entre a anelada dama idealizada e seu amante sofredor. Por outro lado, o amor e a impossibilidade da sua plena realização por causa das severas restrições morais da época, teriam desencadeado o surgimento desse amor idealizado como um meio de fuga, ainda que nos limites da ficção literária, de uma sociedade altamente repressiva. 
O Amor Cortês, em suma, deleita, mas faz sofrer, aprimora, mas fragiliza, erotiza, mas idealiza, educa, mas enlouquece, submete, mas enobrece. Emoções e resultados os mais contraditórios harmonizam no seu seio, nas vidas intensas dos trovadores, nos seus poemas apaixonados. Em todo o caso, proclama a autonomia dos sentimentos face à racionalidade medida pelo saber erudito, face à religiosidade controlada pela Igreja na sua forma ortodoxa, face aos poderes e micropoderes exercidos pela família e pela sociedade para conservar o indivíduo sob o jugo de seus imperativos principais. A seu modo, o Amor Cortês representa uma revolução nos modos de pensar e de sentir, e não deixa de empreender uma velada crítica aos padrões repressores de seu tempo. Uma revolução imaginária, a bem dizer, pois se alguns trovadores a viveram de maneira concreta e intensa, a maioria dos homens e mulheres apenas a vivenciaram de forma lúdica e no mundo da imaginação (BARROS, 2015, p. 221).

O mesmo autor ainda observa outros possíveis fatores que favoreceram a aparição desse gênero amoroso. Entre eles, e como já observamos linhas acima, a crítica à dura repressão da época ou a necessidade das diferentes cortes europeias, acorde com os tempos de mudança e a chegada dos modos mais refinados de convivência da nobreza. Estamento que tinha deixado atrás os castelos e tudo o que eles simbolicamente representavam nos aspectos bélicos, na rudeza dos cavaleiros e no pouco ou nenhum interesse cultural e tinha mudado para o palácio com seus refinados modos de comportamento. Assim, o amor cortês se converte, de acordo com Barros (2011), nesse caldo de cultivo, em um veículo de aperfeiçoamento moral, a porta de entrada para um novo modo de entender relações sociais nas quais o homem era o grande protagonista e a mulher o elemento acessório. O ponto culminante dessa cruzada pelo aprimoramento formal será a publicação em 1528 do livro de Baltasar de Castiglione, $O$ cortesão. Este pequeno tratado sobre os corretos modos de proceder na corte será o digno herdeiro do Tratado do amor cortês, de André Capelão, escrito no final do século XII, e como já fez seu predecessor, nos deixa um retrato da mulher que não condiz muito com a ideia de um amor cortês pensado para exaltar o afeto entre o homem e a mulher, e muito menos para endeusar a gentildonna, como a designa o autor italiano. Para Castiglione, no que se refere à mulher, toda a formação intelectual e toda a estilização de seus modos de conduta possuem um objetivo único: satisfazer o homem. No livro terceiro do seu tratado sobre a Cortesia, Castiglione, através de um diálogo entre o Magnífico (Lorenzo de Médici) e o douto Gaspar Pallacvino, o autor disserta sobre a condição natural da mulher e nos traz um particular retrato de época do pensamento que sobre esta tinham os seus contemporâneos.

Deixando aquelas virtudes da alma que são a elas comuns com o cortesão, como é a prudência, a grandeza do ânimo, a continência e muito outro e assim mesmo aquelas qualidade que se requerem em todas as mulheres, como ser boa e discreta, saber reger a fazenda do marida e a casa e os filhos, se fosse casada, e todas aquelas partes que são afazeres de uma senhora de sua casa, digo que a que anda em um corte ou em 
outro lugar onde de tratem coisa de gala, me parece que de nenhuma coisa tenha necessidade com de certa afabilidade graciosa, com a qual saiba tratar e ter corrente com toda sorte de homens honrados, tendo com eles uma conversa doce e honesta $\mathrm{e}$ conforme ao tempo e ao lugar e a qualidade daquela pessoa com que falar. [...] mas isto com tal maneira de sesso e de bondade o faça, quem em opinião de todos seja tão boa, prudente e bem criada, quando graciosa, avisada e discreta (CASTIGLIONE, 2000 , p. 232-3, tradução do autor). ${ }^{7}$

\section{O papel da mulher no mundo medieval}

Tal e como já observamos no ponto anterior, o refinamento da corte e a materialização na literatura desses modos de conduta através do amor cortês não se traduziram em uma melhor condição de vida da mulher medieval. A idealização da dama e o amor devotado a esta, não foram senão um modo de exaltar as qualidades do cavalheiro frente a seu senhor, e assim o serviço devotado à dama metaforizava as relações de vassalagem entre homens, no qual, como já observamos, a mulher exerce um papel secundário e somente é aproveitada para enfatizar as virtudes masculinas.

Assim, ao tratar da cortesia, são muitas outras as possíveis interpretações por trás do surgimento do amor cortês na literatura e do, às vezes, trato exagerado dado à figura feminina quando pensamos nas reais condições em que esta vivia. Desde o seu nascimento, a mulher nobre tinha o seu destino traçado pela família: nos primeiros anos, a sua educação estava destinada, como se pode ver na citação do livro de Castiglione, a preparar ela para o casamento e para satisfazer as obrigações impostas pela sociedade para com seu esposo e seus futuros descendentes. Por fora desse panorama, no mundo concreto e rude, como adverte Barros (2011) foram poucas as liberdades que as mulheres nobres gozaram e, também, pouco favorável o trato recebido por elas.

Ao mesmo tempo, outros autores discerniram, nesse refinado proceder e na idealização negativa da mulher, a mão da Igreja:

Ao considerar as ideias medievais características a respeito da mulher, é importante saber não só em que consistiam tais ideias, mas também quais eram as fontes das quais surgiram. A opinião expressada de uma época depende das pessoas e das classes que a articulam; por esses motivos representam - frequentemente - a visão de uma minoria pequena, mas com voz. Na primeira Idade Média, o que aparecia como opinião

\footnotetext{
${ }^{7}$ No original: "Así que dejando aquellas virtudes del alma que le son a ellas comunes con el cortesano, como es la prudencia, la grandeza del ánimo, la continencia y muchas otras y asimismo aquellas calidades que se requieren en todas las mujeres, como ser buena y discreta, saber regir la hacienda del marido y la casa y los hijos, si fuere casada, y todas aquellas partes que son menester en una señora de su casa, digo que la que anda en una corte o en otro lugar donde se traten cosas de gala, paréceme que de ninguna cosa tenga tanta necesidad como de una cierta afabilidad graciosa, con la cual sepa tratar y tener correa con toda suerte de hombre honrados, teniendo con ellos una conversación dulce y honesta y conforme al tiempo y al lugar y a la calidad de aquella persona con quien hablare. (...) pero esto con tal manera de seso y de bondad lo haga, que en opinión de todos sea tan buena, prudente y bien criada, cuanto graciosa, avisada y discreta."
} 
contemporânea surgia de duas fontes: a igreja e a aristocracia. Em outras palavras, as ideias das mulheres se formaram de uma parte por clérigos, normalmente celibatários, e de outra, por uma pequena casta que tinha meios econômicos para considerar as suas mulheres como objetos de adorno, em tanto que às subordinavam estritamente ao primeiro objeto de seu interesse: a terra. Efetivamente, se pode dizer com inteira verdade que a teoria aceita a respeito da natureza e o mundo das mulheres devia-se às classes menos familiarizadas com a grande massa do sexo feminino (POWER, 1979, p. 14 , tradução do autor). ${ }^{8}$

A imagem da mulher, como observa Duby (1998), encontrava seu mais obtuso simbolismo na dicotômica representação desta, induzida pelos religiosos, através das simbólicas figuras de Eva e de Ave, a companheira de Adão no jardim do Éden e a mãe de Jesus Cristo, respectivamente. Se a primeira representação, por meio da primeira mulher do cristianismo, condenava seus descendentes a um pecado original que por sua causa condicionava toda a vida terrenal da humanidade, o segundo perfil, carregado de uma maternal delicadeza e de uns atributos positivos que poderiam levar a pensar que seria o contraponto da outra imagem, destinava a esposa, a mãe a um segundo plano que lhe relegava somente aos cuidados da família e a completa submissão a seu marido. Era assim que a mulher se aproximava a esse ideal de perfeição que lhe conectava com a imagem da Virgem Maria.

Quando nos referimos estritamente à literatura e à relevância que a figura de Maria vai ganhar nos últimos séculos do período medieval não podemos tampouco deixar de observar que essa aproximação à figura maternal da mãe de Cristo, o espelho no qual se deveria refletir toda mulher, não é senão uma calculada idealização a serviço de uma causa. A consolidação de Maria como advogada da humanidade, a mulher que se compadece do pecador diante de Cristo obedece a uma necessidade de ordem prática e não a benéfica exaltação da mulher concreta. $\mathrm{O}$ despertar laico que se vai produzir nos derradeiros séculos da Idade Média e o paulatino distanciamento de uma sociedade cada vez mais prática, menos dependente da igreja e alheia às sufocantes práticas de uma igreja cada dia mais longe do povo, vão provocar a necessidade de encontrar outro elo, mais humano e atraente, entre a igreja e seu feligres. E caberá a Maria ser a escolhida para representar esse papel apaziguador, essa referência familiar que todos

\footnotetext{
${ }^{8}$ No original: "Al considerar las ideas medievales características acerca de la mujer, es importante saber no sólo en qué consistían dichas ideas sino también cuáles eran las fuentes de las que surgieron. La opinión expresada de una época depende de las personas y de las clases que la articulan; por este motivo representan - a menudo la visión de una minoría pequeña pero con voz. En la temprana Edad media, lo que aparecía como opinión contemporánea surgía de dos fuentes: la iglesia y la aristocracia. En otras palabras, las ideas sobre la mujer se formaron, de una parte, por los clérigos - normalmente célibes - y de otra, por una pequeña casta que tenía medios económicos para considerar a sus mujeres como objetos de adorno, en tanto que las subordinaban estrictamente al primero objeto de su interés: la tierra. Efectivamente, puede decirse con entera verdad que la teoría aceptada acerca de la naturaleza y el mundo de las mujeres se debía a las clases menos familiarizadas con la gran masa del sexo femenino."
} 
conseguem identificar como algo mais próximo e positivo; a mariologia desperta, através da literatura e das multitudinárias obras hagiográficas, a figura da mulher (Eva) como novo parâmetro, porém isso não se traduz, claro está, em uma melhora da condição feminina entre as mulheres que aclamavam a esta imagem devota.

Outros críticos como Guy de Lobrichon (1994, apud Rodríguez, 2008) enxergam nesse despertar mariano, nessa promoção da mulher, uma manifestação derivada do que ele denomina de "religião dos laicos":

\begin{abstract}
A religião popular em geral e mariana em particular, não costuma se esgotar em celebrações litúrgicas oficiais, mas que se expressa em manifestações festivas que possuem uma mistura de fervor religioso e de lucidez mundana. Essas manifestações podem por em risco a ortodoxia, dai que a Igreja empregue meios pastorais diversos, canônicos e litúrgicos para controlar, corrigir e inclusive dirigir de forma direta as expressões populares da religião e, em concreto, da devoção mariana. [...] Este sincretismo pode ser observado, por exemplo, a partir do século XVIII na iconografia religiosa, dominada pela figura de Cristo sofredor e pela mulher. Esses séculos são de promoção da mulher, cujo modelo na Virgem preferentemente. A essas manifestações religiosas Guy Lobrichon chamou faz alguns anos "a religião dos laicos" (RODRÍGUEZ, 2008, p. 5, tradução do autor). ${ }^{9}$
\end{abstract}

\title{
O ideal cavalheiresco e suas outras significações
}

Diante de tudo exposto anteriormente, a figura do cavalheiro medieval é refletida na literatura medieval como a soma de todos os aspectos considerados até agora; na sua valentia, no seu devotado amor pela dama de seus sonhos e principalmente pela sua possibilidade de ascensão social através da carreira das armas em um mundo caraterizado pelo tradicionalmente considerado imobilismo social.

Por trás da exaltada façanha do cavalheiro, carregada de aventuras, de perigos, de amores impossíveis e da indiscutível lealdade a um honorável código cavalheiresco, os cantares de gesta e, posteriormente os romances de cavalaria, revelam outros valores, outras significações as quais, ainda que dentro desse nobre código, nos delatam as não tão dignas intenções por trás desse idealizado mundo de aventuras. Para Sánchez Albornoz (1979), o castelhano Romance do Mio Cid, além das heroicas vicissitudes pelas quais passa o cavalheiro homônimo, por trás

\footnotetext{
${ }^{9}$ No original: "La religiosidad popular en general y la mariana en particular no suele agotarse en celebraciones litúrgicas oficiales, sino que se expresa en manifestaciones festivas que tienen una mezcla de fervor religioso y de lucidez mundana. Estas manifestaciones ponen en riegos la ortodoxia, de alli que la Iglesia emplee medios pastorales diversos, canónicos y litúrgicos para controlar, corregir e incluso dirigir de forma directa las expresiones populares de la religiosidad y, en concreto, de la devoción mariana. [...] Este sincretismo puede observarse, por ejemplo, a partir del siglo XIII en la iconografía religiosa, dominada por la figura de Cristo sufriente y por la mujer. Estos siglos son de promoción de la mujer, cuyo modelo en la Virgen preferentemente. A estas manifestaciones religiosas Guy Lobrichon llamó hace unos años «la religión de los laicos".
} 
das aventuras, traições, humilhações e do perdão final, reflete nos bastidores o pensamento de uma sociedade castelhana dividida entre a poderosa aristocracia e os cavalheiros de armas. Ao mesmo tempo, o historiador observa que, além da coragem e da galhardia dos soldados, existe um desejo de medro, de ascensão social através da guerra em uma sociedade que oferecia limitadas possibilidades de crescimento tanto social como econômico.

No "Cantar del Cid", é importante perceber a constante atenção de julgar Medinaceli,
desde o começo do poema, a respeito dos bens materiais. A riqueza, o medro. [...] Os
cantares de gesta castelhanos tinham não pouco de sustância política.
O de Mío Cid mostra grande animosidade contra a alta aristocracia e férvida
admiração pelos infazones e cavaleiros, filhos de suas obras mais do que da sua estirpe
e de sua riqueza; não alcança ocultar uma clara hostilidade ao rei e descobre uma
vívida inimizade contra os judeus, explicável pela crescente pressão econômica que
exerciam sobre os demais ao amparo dos príncipes (ALBORNOZ, 1979, p. 26-27).

Assim, a leitura em entrelinhas desse pioneiro gênero cavalheiresco nos oferece outra visão da sociedade medieval e nos permite, assim, aproximar-nos de forma mais nítida do contexto social deste estigmatizado período da nossa história para reconhecer, como já notamos antes, uma sociedade dividida e com fortes desejos de mudança. As palavras do jogral nas praças das cidades ou das pequenas vilas nas quais ele parava para oferecer a sua arte e ganhar umas moedas em troca, podemos imaginar que refletiam o desejo vivo de um público. Um espectador que, apesar de iletrado e cansado de sua injusta condição social, podia inferir e até sonhar, nos bastidores desses cantares de gesta, com uma porta que se abria para a mudança. E claro está, o artista de rua enriquecia as suas narrações orais, as suas criações artísticas, com esses anseios diretos do povo. Jogava-se assim, como observa o próprio Albornoz, a semente do desdém, essa que com o tempo daria os seus frutos.

\section{Considerações finais}

Como vimos através dos quatro aspectos tratados nas linhas anteriores, um olhar menos conservador e mais abrangente da literatura do período nos pode ajudar a traçar uma imagem alternativa do mundo medieval. Uma representação que fuja dos padrões convencionais aos que

\footnotetext{
${ }^{10}$ No original: "En el Cantar del Cid, importa percibir la constante atención del juglar de Medinaceli, desde el comienzo del Poema, hacia los bienes materiales. La riqueza, el medro. [...] Los cantares de gesta castellanos tenían no poco de sustancia política. El de Mio Cid rebosa rencor contra la alta aristocracia y férvida admiración hacia los infanzones y caballeros, hijos de sus obras más que de su estirpe y de su riqueza; no logra ocultar una clara hostilidad al rey y descubre una vivaz enemiga a los judios, muy explicable por la creciente presión económica que ejercían sobre el demos al amparo de los príncipes."
} 
estamos acostumados a ver quando nos referimos a essa controversa "Idade das trevas". A visão poliédrica, postulada pelo Novo Medievalismo, nos ajuda a viajar no tempo com o auxílio de outras disciplinas como a história, a sociologia ou a paleografia, entre outras, e é na junção desses saberes que as ricas manifestações literárias ganham novas interpretações, com a sua equilibrada dose de preterismo e de presentismo como observa Aurell (2016). Parafraseando ao poeta castelhano Jorge Manrique, podemos concluir que todo tempo passado pode ser melhor se sabemos enxergá-lo na sua plena dimensão. Para o já citado Claudio Sánchez Albornoz, a literatura burguesa, com a sua visão prática do mundo, abusa de seu espírito burlesco para criticar uma sociedade que almejava uma mudança social e vai ser através da ironia, da paródia, do humor que essa porta irá se abrir aos poucos. E a literatura, na boca desses artistas do povo, será a encarregada desse câmbio de mentalidade que provocará muitas alterações nos derradeiros momentos da denominada Idade Média. E ainda que essas transformações sociais se dilatem no tempo e o Medievo chegue até o século XVII, como assevera Le Goff (2014), a semente, entre risos e burlas, já tinha sido colocada e com o tempo daria seus frutos. Nas entrelinhas desses textos podemos hoje, através de novos modos de análise menos estigmatizados, encontrar outro imaginário revelado que difira muito daquele apresentado pela história mais tradicional.

\footnotetext{
Enquanto teve de dissidência, de ruptura e de novidade frente ao teocêntrico, o cavalheirismo, a vassalagem, o senhorio..., o espírito burguês começou a se manifestar mediante burlas, mais ou menos vivas, de tudo que havia constituído até ali o eixo da vida medieval. Mediante burlas pronunciadas por homens inquietos e carregados de humorismo, que ao contemplar o mundo em torno sentiam estourar-lhes no peito uma gargalhada, mas positiva que sanhuda, ante ideias, instituições, práticas, usos, fórmulas até ali ancoradas e em comum assentamento, mas que começavam a perder autenticidade vital. Eles captavam esse inicio de caducidade: a queda de seu prestigio, o esvaziamento da sua sustância interna, o seu desarraigo da terra firme, do assenso geral... O captavam quando ainda não quebravam os albores dessa nova jornada histórica. Começavam a ver as facetas cômicas e histriônicas do presente ainda consagrado pelo respeito de aqueles que não eram capazes de alçar-se criticamente frente ao recebido das gerações anteriores. Só a inquietude e a ironia poderiam disparar raios infravermelhos contra os tecidos que começavam a degenerar na subestrutura do corpo social, ainda em atividade plena (ALBORNOZ, 1979, p. 29-30, tradução do autor). ${ }^{11}$
}

\footnotetext{
${ }^{11}$ No original: "En cuanto tuvo de disidencia, de ruptura y de novedad frente a lo teocéntrico, lo caballeresco, lo vasallático, lo señorial... el espíritu burgués empezó a manifestarse mediante burlas, más o menos vivaces, de todo lo que había constituido hasta allí el eje de la vida medieval. Mediante burlas salidas de hombres inquietos y cargados de humorismo, que al contemplar el mundo en torno sentían estallarles en el pecho una carcajada, más benévola que sañuda, ante ideas, instituciones, prácticas, usos, fórmulas ... hasta allí ancladas en el común asentimiento pero que empezaban a perder autenticidad vital. Ellos captaban ese inicio de caducidad: la caída de su prestigio, el vaciamiento de su sustancia interna, su desarraigo de la tierra firme del asenso general. Lo captaban cuando todavía no quebraban albores a la aurora de la nueva jornada histórica. Empezaban a ver las facetas cómicas y bufonescas del presente aún consagrado por el respeto de quienes no eran capaces de alzarse críticamente frente a lo recibido de las generaciones anteriores. Sólo la inquietud y la ironía podían disparar
} 
O humor, a burla satírica contra as instituições mais sólidas de cada época pôde ajudar a esboçar, através da análise proposta pelo Novo Medievalismo, outro imaginário menos tradicionalista, porém isso aqui já é ou será outra história.

\section{Referências}

AURELL, J. El nuevo medievalismo y la interpretación de los textos históricos. Hispania. Revista Española de Historia, Navarra, v. 66, n. 224, p. 809-832, set./dez. 2006.

La historiografía medieval. Entre la historia y la literatura. Valencia: PUV, 2016.

. Medievalismo y medievalistas en el siglo XX. Anuario de Historia de la Iglesia, Navarra, v. 13, p. 383-386, 2004. Disponível em:

<www.unav.edu/publicaciones/revistas//index.php/anuario-de-historiaiglesia/article/viewFile/23634/20610> .Acesso em: 20 jun. 2020.

BARROS, J. D. A. A poética do amor cortês e os trovadores medievais - caracterização, origens e teorias. Aletria, Belo Horizonte, v. 25, n. 1, p. 215-228, 2015. Disponível em: <www.periodicos.letras.ufmg.br/index.php/aletria/article/view/6290>. Acesso em: 20 jun. 2020.

BARROS, J. D. A. O Amor Cortês - suas origens e significados. Raido, Dourados, MS, v. 5, n. 9, p. 195-216, jun. 2011. Disponível em:

<https://ojs.ufgd.edu.br/index.php/Raido/article/view/979\#>. Acesso em: 20 jun. 2020.

CAPELAO, A. Tratado do amor cortês. São Paulo: Martins Fontes, 2000.

CASTIGLIONE, B. El cortesano. Madri: Ed. Espasa, 2000.

DUBY, G. Eva y los sacerdotes. Madri: Alianza Editorial, 1998.

ESTRADA, F. L. Introducción a la literatura medieval española. 5. ed. Madri: Editorial Gredos, 1983.

FACINA, A. Literatura e sociedade. Rio de Janeiro: Jorge Zahar, 2004.

FRANCO JR., H. A Idade Média: nascimento do ocidente. 2. ed. rev. e ampliada. São Paulo: Brasiliense, 2001.

FRANCO JR., H. As utopias medievais. São Paulo: Brasiliense, 1992.

GARCÍA, A. R. La Edad Media. Un concepto problemático y multifuncional. Destiempos. Revista de Curiosidad Cultural, n. 38, p. 7-16, 2014. Disponível em: $<$ https://dialnet.unirioja.es/servlet/articulo?codigo=4671581>. Acesso em: 20 jun. 2020.

rayos infrarrojos hacia tejidos que empezaban a degenerar en la subestructura del cuerpo social, todavía en plena actividad." 
LE GOFF, J. A história deve ser dividida em pedaços? Tradução de Nícia Adan Bonatti. São Paulo: Editora Unesp, 2015.

LE GOFF, J. Para um novo conceito de Idade Média. Tradução de Maria Helena da Costa Dias. Lisboa: Editora Estampa, 1979.

LE GOFF, J. ¿Realmente es necesario cortar la historia en rebanadas? Cidade do México: Fondo de cultura económica, 2016.

LE GOFF, J. Uma longa Idade Media. Tradução de Marcos de Castro. Rio de Janeiro: Civilização brasileira, 2008.

MACEDO, J. R. Imaginário carnavalesco, riso e utopia nos Fabliaux medievais. Revista de História, São Paulo, n. 132, p. 19-28, 1995. Disponível em:

<www.revistas.usp.br/revhistoria/article/view/18751/20814>. Acesso em: 20 jun. 2020.

MINGUEZ, C.G. La construcción de la Edad Media: Mito y realidad. Palência: PITTM, 2006. Disponível em: <https://es.scribd.com/document/207585549/Dialnet-

LaConstruccionDeLaEdadMedia-2335958>. Acesso em: 09 set. 2020.

SOLARES, B. La investigación del imaginario medieval. Cultura y representaciones sociales, Cidade do México, v. 1, n. 2, p. 139-152, 2007. Disponível em:

$<$ www.scielo.org.mx/scielo.php?script=sci_arttext\&pid=S2007-

$81102007000100007 \& \operatorname{lng}=$ es\&tlng=es>. Acesso em: 10 out. 2020.

PERNOUD, R. O Mito da Idade Média. Tradução de Maria do Carmo Santos. Lisboa:

Publicações Europa - América, 1978.

POWER, E. Mujeres medievales. Madri: Ediciones Encuentro, 1979.

RICO, F.; DEYERMOND, A. Historia y critica de la Edad Media. Barcelona: Ed. Crítica, 1979.

RODRÍGUEZ, G. Los milagros en la religiosidad hispánica (siglos XIII al XVI). Bulletin du centre d'études médiévales d'Auxerre - BUCEMA, Auxerre, n. 2, 2008, disponibilizado em linha em 13 jan. 2009. Disponível em: <http://journals.openedition.org/cem/9002>. Acesso em: 04 dez. 2020. DOI : https://doi.org/10.4000/cem.9002.

Recebido em: 24/07/2020 Aceito para publicação em: 25/08/2020 